\title{
Synthesis and Antibacterial and Antibiofilm Activity of Iron Oxide Glycerol Nanoparticles Obtained by Coprecipitation Method
}

\author{
Simona Liliana Iconaru, ${ }^{1}$ Alina Mihaela Prodan, ${ }^{2,3}$ \\ Philippe Le Coustumer, ${ }^{4}$ and Daniela Predoi ${ }^{1}$ \\ ${ }^{1}$ National Institute of Materials Physics, 105 bis Atomistilor, P.O. Box MG 07, Magurele, 077125 Bucharest, Romania \\ ${ }^{2}$ Carol Davila University of Medicine and Pharmacy, 8 Eroii Sanitari, Sector 5, Bucharest, Romania \\ ${ }^{3}$ Floreasca Emergency Hospital, Bucharest 5, Calea Floresca no. 8, Sector 1, Bucarest, Romania \\ ${ }^{4}$ EA 4592 Géoressources \& Environnement, EGID and Université de Bordeaux 1 allée F. Daguin 18, 33607 Pessac Cedex, France
}

Correspondence should be addressed to Daniela Predoi; dpredoi@gmail.com

Received 23 June 2012; Accepted 30 July 2012

Academic Editor: Gulaim A. Seisenbaeva

Copyright (C) 2013 Simona Liliana Iconaru et al. This is an open access article distributed under the Creative Commons Attribution License, which permits unrestricted use, distribution, and reproduction in any medium, provided the original work is properly cited.

\begin{abstract}
The glycerol iron oxide nanoparticles (GIO-NPs) were obtained by an adapted coprecipitation method. The X-ray diffraction (XRD) studies demonstrate that GIO-NPs were indexed into the spinel cubic lattice with a lattice parameter of $0.835 \mathrm{~nm}$. The refinement of XRD spectra indicated that no other phases except maghemite were detected. The adsorption of glycerol on iron oxide nanoparticles was investigated by Fourier transform infrared (FTIR) spectroscopy. On the other hand, this work implicated the use of GIO-NPs in antibacterial studies. The results indicate that, in the case of P. aeruginosa 1397 biofilms, at concentrations from $0.01 \mathrm{mg} / \mathrm{mL}$ to $0.625 \mathrm{mg} / \mathrm{mL}$, the glycerol iron oxide inhibits the ability of this strain to develop biofilms on the inert substratum.
\end{abstract}

\section{Introduction}

In the previous decades the nanotechnology progress has made possible the understanding of matter at a fundamental level. Due to the outstanding properties exhibited by various materials when investigated at the nanometric scale, the scientific community focused on developing new ways of synthesizing engineered nanoparticles. Nowadays, the most investigated nanomaterials are the inorganic ones due to their novel and improved physical, chemical, and biological properties [1-6]. Because they exhibit very good electric, optical, electronic, magnetic, and biological properties, these nanoparticles have been widely studied for their use in pharmaceutical, medical, and environmental applications.

Nanoparticles with magnetic behavior are one of the most interesting materials due to their broad-wide possible applications in fields such as environment, medical applications, electronics, media recording devices and Iron oxides nanoparticles, mostly magnetite and maghemite, have been the subject of numerous studies concerning their use in magnetic resonance imaging (MRI), cell labeling, and hyperthermia. Being the only types of magnetic nanoparticles with proven biological properties and good biocompatibility, iron oxides are still in the researchers priorities even though these nanoparticles have been intensively studied and characterized during the years $[7,8]$.

Magnetite with the general formula $\mathrm{Fe}_{3} \mathrm{O}_{4}$ and its oxidized form maghemite $\left(\gamma-\mathrm{Fe}_{2} \mathrm{O}_{3}\right)$ are suitable to be used in biomedical application due to their biological properties, superparamagnetic behavior, and controllable parameters [4-6]. Due to their unique properties attempts were made to introduce these nanoparticles in other fields of applications $[9,10]$. Recent studies have been focused on finding new and improved antibacterial agents. The search for new materials having inhibitory effect on the growth of various microorganisms reached the area of nanomaterials [11]. Nanoparticles were chosen because they can interact with microbial cells directly by disrupting/penetrating the cell envelope, produce secondary products, dissolved heavy metal ions, interrupting transmembrane electron transfer, or indirectly being the 
carrier for other substances with antibacterial properties [1214]. Studies show that metals have proven to affect bacterial growth kinetics and have a high influence against bacterial strains growth [15].

\section{Materials and Methods}

2.1. Materials. Ferrous chloride tetrahydrate $\left(\mathrm{FeCl}_{2} \cdot 4 \mathrm{H}_{2} \mathrm{O}\right)$, ferric chloride hexahydrate $\left(\mathrm{FeCl}_{3} \cdot 6 \mathrm{H}_{2} \mathrm{O}\right)$, natrium hydroxide $(\mathrm{NaOH})$, and clorhidric acid $(\mathrm{HCl})$, nitric acid $\left(\mathrm{HNO}_{3}\right)$, and ferric nitrate nonahydrate $\left(\mathrm{FeNO}_{3} \cdot 9 \mathrm{H}_{2} \mathrm{O}\right)$ were purchased from Merck. Glycerol (99.5\%) was purchased from Sigma. Deionized water was used in the synthesis of nanoparticles and for rinsing of clusters.

\subsection{Synthesis of Glycerol Iron Oxide Ferrofluid. Glycerol} iron oxide nanoparticles were prepared by coprecipitation according to [16-19]. Glycerol solution $(60 \mathrm{~mL}$ in $200 \mathrm{~mL}$ of $\mathrm{NaOH}\left(2 \mathrm{~mol} \cdot \mathrm{L}^{-1}\right)$ was agitated under vigorous stirring for about $2 \mathrm{~h}$. Ferrous chloride tetrahydrate $\left(\mathrm{FeCl}_{2} \cdot 4 \mathrm{H}_{2} \mathrm{O}\right)$ in $2 \mathrm{M} \mathrm{HCl}$ and ferric chloride hexahydrate $\left(\mathrm{FeCl}_{3} \cdot 6 \mathrm{H}_{2} \mathrm{O}\right)$ were mixed at room temperature $\left(\mathrm{Fe}^{2+} / \mathrm{Fe}^{3+}=1 / 2\right)$. The mixture was dropped into glycerol solution under vigorous stirring. The precipitate of magnetite (black precipitate immediately formed) was converted into $\gamma$ - $\mathrm{Fe}_{2} \mathrm{O}_{3}$ particles by repeated treatment with $\mathrm{HNO}_{3}\left(2 \mathrm{~mol} \cdot \mathrm{L}^{-1}\right)$ and ferric nitrate nonahydrate $\left(0.3 \mathrm{~mol} \cdot \mathrm{L}^{-1}\right)$ solutions according to [19, 20]. The acidic precipitate was isolated by decantation on a magnet, separated by centrifugation (12000 rpm), washed, and dispersed in deionized water at $\mathrm{pH}=2.5$. The final ion concentration was $0.38 \mathrm{~mol} \cdot \mathrm{L}^{-1}$.

2.3. Sample Characterization. The X-ray diffraction measurements for the iron oxide samples were recorded using a Bruker D8 Advance diffractometer, with nickel filtered $\mathrm{Cu}$ $\mathrm{K}_{\alpha}(\lambda=1.5418 \AA)$ radiation, and a high efficiency onedimensional detector (Lynx Eye type) operated in integration mode. The diffraction patterns were collected in the $2 \theta$ range $20^{\circ}-70^{\circ}$, with a step of $0.02^{\circ}$ and $34 \mathrm{~s}$ measuring time per step. Transmission electron microscopy (TEM) images for these samples were recorded using an FEI Tecnai 12 equipped with a low-dose digital camera from Gatan. The specimen for TEM imaging was prepared by ultramicrotomy to get thin section of about $60 \mathrm{~nm}$. The powder was embedded in an epoxy resin (polaron 612) before microtomy. TEM modes used were Bright Field (BF) and Selected Area Diffraction (SAD). The functional groups present in the prepared nanoparticles and thin films were identified by FTIR using a Spectrum BX spectrometer. To obtain the nanoparticles spectra, $1 \%$ of the nanopowder was mixed and ground with $99 \% \mathrm{KBr}$. Tablets of $10 \mathrm{~mm}$ diameter were prepared by pressing the powder mixture at a load of 5 tons for $2 \mathrm{~min}$. The spectrum was recorded in the range of 500 to $4000 \mathrm{~cm}^{-1}$ with $4 \mathrm{~cm}^{-1}$ resolution.

2.4. The In Vitro Antibacterial and Antibiofilm Activity. Assessment of the Antimicrobial and Antipathogenic Activity of the New Oxides. The in vitro qualitative screening of the antimicrobial activity was carried out by an adapted agar diffusion technique using a bacterial suspension of 0.5 McFarland density obtained from 24-hour cultures. The antimicrobial activities of the GIO-NPs were determined against microbial clinical and ATCC reference strains, that is, P. aeruginosa 1397 and E. faecalis ATCC 29212 strains The microbial strains identification was confirmed by aid of VITEK II automatic system. VITEK cards for identification and susceptibility testing (GNS-522) were inoculated and incubated according to the manufacturer's recommendations. The results were interpreted by using software version AMS R09.1. GIO-NPs were suspended in dimethyl sulfoxide to a final concentration of $10 \mathrm{mg} / \mathrm{mL}$. A volume of $10 \mu \mathrm{L}$ of each tested sample was distributed directly on the solid medium previously seeded with the microbial inocula. The inoculated plates were incubated for $24 \mathrm{hrs}$ at $37^{\circ} \mathrm{C}$. Antimicrobial activity was assessed by measuring the growth inhibition zones diameters expressed in $\mathrm{mm}$ [21-23]. Following the results of the qualitative screening, only the microbial strains proving to be susceptible have been further tested in the quantitative assay.

The Quantitative Assay of the Minimal Inhibitory Concentration $(M I C, \mu g / m L)$. It was based on liquid medium twofold microdilutions and performed in 96 multiwell plates. In this purpose, serial binary dilutions of the tested compounds (ranging between 5 and $0.01 \mu \mathrm{g} / \mathrm{mL}$ ) were performed in a $200 \mu \mathrm{L}$ volume of nutrient broth/YPG and each well was seeded with $20 \mu \mathrm{L}$ microbial inocula of $0.5 \mathrm{McF}$ arland density. The plates were incubated for 24 hours at $37^{\circ} \mathrm{C}$ for bacterial strains, and the antibacterial effect was assessed by measuring the absorbance of the obtained culture at $620 \mathrm{~nm}$ [21-23].

The Antibiofilm Activity of the GIO-NPs. It was tested by the microtiter method. For this purpose, the microbial strains have been grown in the presence of twofold serial dilutions of the tested compounds performed in liquid nutrient broth/YPG, distributed in 96-well plates, and incubated for 24 hours at $37^{\circ} \mathrm{C}$ for bacterial strains. At the end of the incubation period, the plastic wells were emptied, washed three times with phosphate buffered saline (PBS), fixed with cold methanol, and stained with $1 \%$ violet crystal solution for 30 minutes. The biofilm formed on plastic wells was resuspended in 30\% acetic acid. The intensity of the colored suspensions was assessed by measuring the absorbance at $492 \mathrm{~nm}[24,25]$.

\section{Results and Discussions}

Figure 1 shows the powder X-ray diffraction (XRD) pattern from the as-prepared sample glycerol iron oxide nanoparticles (GIO-NPs). The peaks can be indexed fcc cubic maghemite structure (ICSD card no. 01-083-0112) and lattice constants $0.835 \mathrm{~nm}$. No impurity peaks were observed, demonstrating a high purity of the final product. The width of the peaks, however, is relatively broad compared with the XRD pattern of bulk maghemite, indicating a small 


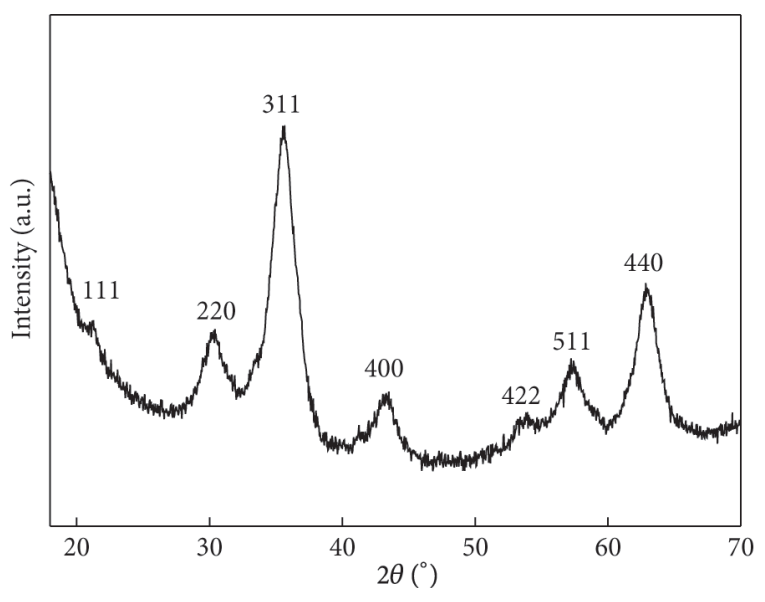

FIGURE 1: XRD pattern of the as-prepared product, indexed as cubic maghemite.

crystal size. The average sizes $\langle D\rangle$ of the nanoparticles were computed using Scherer's formula [26]:

$$
D=\frac{K \lambda}{B} \cos \theta,
$$

where $D$ is the averaged length of coherence domains (that is of perfectly ordered crystalline domains) taken in the direction normal to the lattice plane that corresponds to the diffraction line taken into account, $B$ is the line broadening due to the small crystallite size, $\lambda$ is the wavelength of $\mathrm{X}$-rays (1.5416 $\AA$ ), $\theta$ is the Bragg angle, and $K$ is a constant related to crystallite shape and to the definition of $B$ (integral breadth or full width at half maximum). A crystallite size of GIO-NPs was estimated at around $4.2 \mathrm{~nm}$.

Figure 2(a) presents a magnified TEM image of GIONPs, clearly showing that the product is entirely composed of crystals with a relatively uniform, spherical morphology. Figure 2(b) shows selected area electron diffraction (SAED) pattern recorded from an area containing a large number of nanoparticles. The rings in the SAED pattern can be indexed as the (220), (311), (400), (422), (511), and (440) reflections of the cubic maghemite in agreement with the XRD results. The average grain size of the nanoparticles was $4.7 \pm 0.2 \mathrm{~nm}$.

The attachment of the glycerol on the iron oxide particles surface was investigated by FT-IR spectroscopy. Figure 3 illustrates the FT-IR spectra of GIO-NPs. According to [27] maximum of $1554 \mathrm{~cm}^{-1}$ is attributed to $\mathrm{COO}^{-}$band. The bands in the region $1048-1384 \mathrm{~cm}^{-1}$ are assigned to primary alcohol and the band at $1459 \mathrm{~cm}^{-1}$ represented secondary alcohol in good accord with [27].

The bands at $1516 \mathrm{~cm}^{-1}$ and $1537 \mathrm{~cm}^{-1}$ correspond to $\mathrm{C}-\mathrm{O}-\mathrm{H}$ vibration modes. The bands observed at $2337 \mathrm{~cm}^{-1}$ and $2364 \mathrm{~cm}^{-1}$ are assigned to $\mathrm{C}-\mathrm{O}$ vibration modes. The bands at $2855 \mathrm{~cm}^{-1}$ and $2940 \mathrm{~cm}^{-1}$ are attributed to $\mathrm{C}-\mathrm{H}$ vibration modes. The spectral ranges $1000-1200 \mathrm{~cm}^{-1}$ were due to $v(\mathrm{C}-\mathrm{C})$ and $v(\mathrm{C}-\mathrm{O})$ stretching vibration with contributions from $\delta(\mathrm{C}-\mathrm{O}-\mathrm{H})$ motion [28]. The spectrum of GIO-NPs contains characteristic $\mathrm{OH}$ stretching $v(\mathrm{OH})$ and $\mathrm{HOH}$ bending $(\delta \mathrm{OH})$ vibrational bands at $3440 \mathrm{~cm}^{-1}$ and
$1600 \mathrm{~cm}^{-1}$ due to the adsorbed water molecules in the sample [29]. Since magnetite has an inverse spinel type structure, it shows the characteristic vibrational bands: $\mathrm{M}_{\mathrm{Td}}-\mathrm{O}-\mathrm{M}_{\mathrm{oh}}$ $\left(v_{1} \approx 620-550 \mathrm{~cm}^{-1}\right), \mathrm{M}_{\mathrm{oh}}-\mathrm{O}\left(v_{2} \approx 470 \mathrm{~cm}^{-1}\right)$, and $\mathrm{M}_{\mathrm{Td}}-$ $-\mathrm{M}_{\mathrm{oh}}\left(v_{3} \approx 350-400 \mathrm{~cm}^{-1}\right)$, where $\mathrm{M}_{\mathrm{Td}}$ and $\mathrm{M}_{\text {oh }}$ correspond to the metal occupying tetrahedral and octahedral positions respectively [30,31]. The bands observed at $620 \mathrm{~cm}^{-1}$ and $580 \mathrm{~cm}^{-1}$ corresponds to the stretching vibration $v(\mathrm{Fe}-\mathrm{O})$ of tetrahedral iron atom [32].

Inorganic metal oxides may serve as effective disinfectants, due to their relatively nontoxic profile, chemical stability, and efficient antibacterial activity [33]. The insertion of the prosthetic medical devices for different exploratory or therapeutical purposes, especially in severe pathological conditions, represents a risk factor for the occurrence of chronic infections in developed countries, being characterized by slow onset, middle intensity symptoms, chronic evolution, and resistance to antibiotic treatment [34]. The microbial species of clinical interest, often involved in biofilm-associated diseases, are belonging to a very large spectrum, from the Gram-positive (S. epidermidis and $S$. aureus) to the Gram negative pathogens ( $P$. aeruginosa, E. coli) and to different members of the Candida genus [35]. The understanding of microbial infections related to the biofilm development on tissues or indwelling devices was possible by using different qualitative and quantitative in vitro specific assays. In our study we have also used both assays for studying the susceptibility of microbial cells grown in suspension, as well as of those developed in biofilms, called planktonic cells.

The qualitative screening of the tested compounds at $10 \mathrm{mg} / \mathrm{ml}$ concentration showed that GIO-NPs were slightly active only on two of the tested strains, that is, E. faecalis 29212 and $P$. aeruginosa 1397. In order to investigate the dose-concentration effects of the tested GIO-NPs, we have further chosen these strains to be tested in the presence of a range of twofold serial dilutions of the tested compounds.

The last decades studies of microbial adherence to different substrata led to the conclusion that the survival of microorganisms in the natural habitats, including medical ecosystems, is dependent on their capacity to adhere to different surfaces/substrata and to form biofilms. A biofilm is a sessile microbial community composed of cells embedded in a matrix of extracellular polymeric substances attached to a substratum or interface. The matrix is primarily of microbial origin and the cells encased in this matrix present a modified phenotype, being metabolically more efficient and well protected, exhibiting resistance to different stress factors, including host defense mechanisms and antibiotics [36]. All tested concentrations of GIO-NPs strongly stimulated the microbial growth in suspension, the intensity of this stimulatory activity being proportional with the tested concentrations in the range $5 \mathrm{mg} / \mathrm{mL}-0.625 \mu \mathrm{g} / \mathrm{mL}$, thereafter entering a plateau in the range $0.313-0.01 \mu \mathrm{g} / \mathrm{mL}$ (Figure 4).

The same general behavior was observed also in case of microbial biofilms, but, in case of P. aeruginosa 1397 biofilms, at lower concentrations, the GIO-NPs inhibited the ability of 


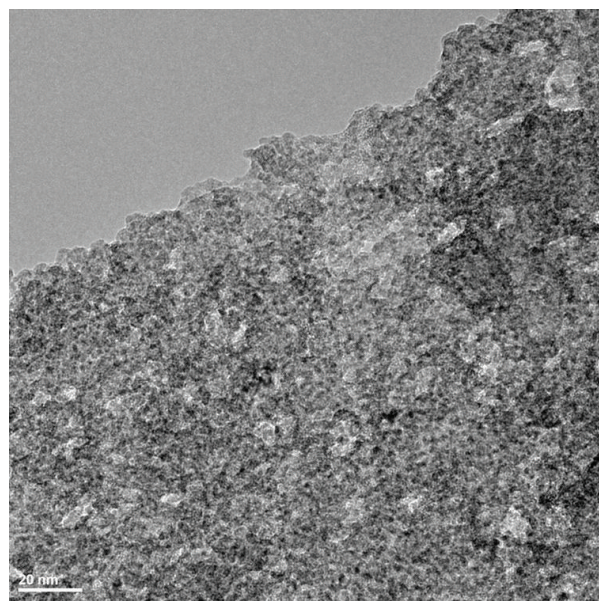

(a)

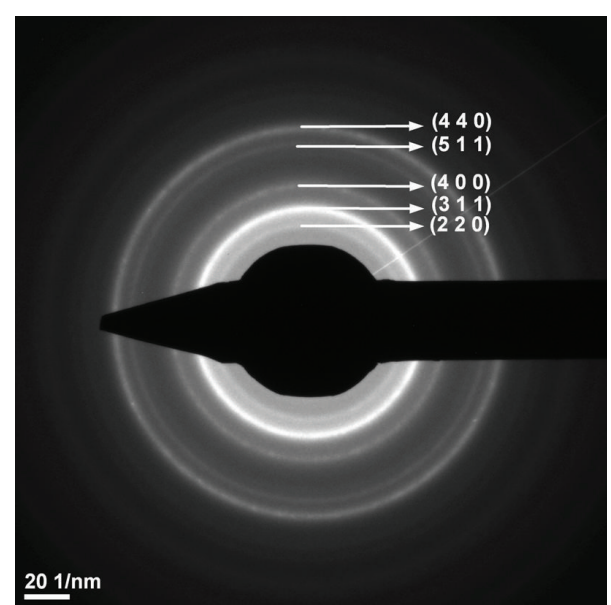

(b)

FIGURE 2: (a) Magnified TEM image of GIO-NPs; (b) SAED pattern from a region including a large number of nanoparticles.

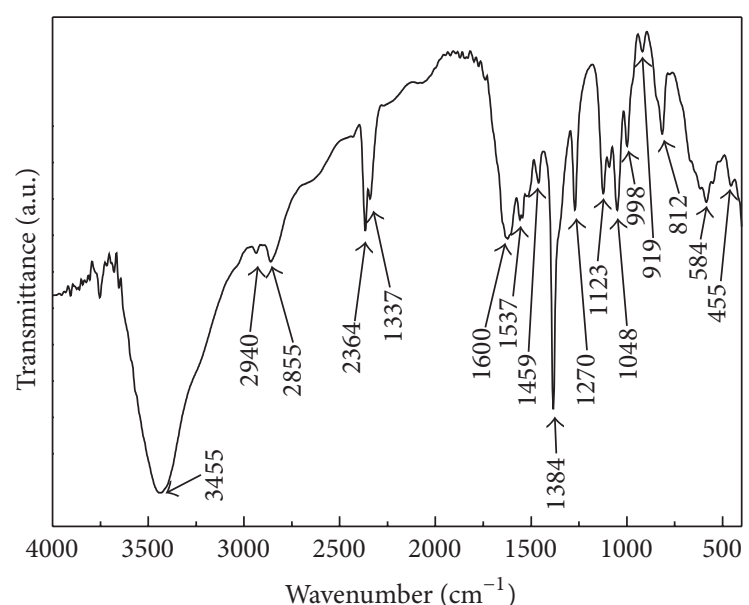

FIGURE 3: Infrared transmittance spectra of spectra of GIO-NPs in the $4000 \mathrm{~cm}^{-1}$ to $400 \mathrm{~cm}^{-1}$ region.

this strain to develop biofilms on the inert substratum (Figure 5).

The GIO-NPs exhibited a dose-dependent inhibitory effect on ability to develop biofilms of the Gram-negative P. aeruginosa 1397 and the Gram-positive E. faecalis ATCC 29212 strains. The GIO-NPs exhibited a strong inhibitory effect for different concentration on $P$. aeruginosa 1397 ability to develop bioflms on the inert substratum.

\section{Conclusions}

Glycerol iron oxide nanoparticles were synthesized by coprecipitation method. An average glycerol iron oxide size of $4.2 \mathrm{~nm}$ was found by X-ray diffraction and a $4.7 \mathrm{~nm}$ was found by transmission electron microscopy. The attachment of the glycerol on the iron oxide particles surface was revealed by Fourier transform infrared (FTIR) spectroscopy. In the

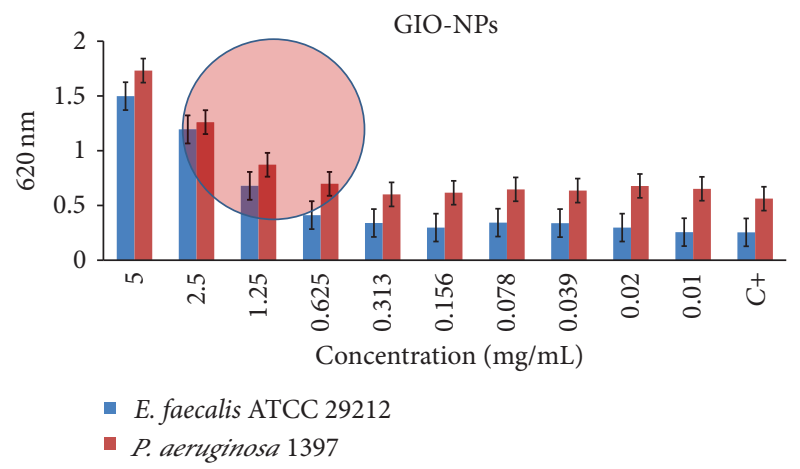

Figure 4: The quantitative assay of the MIC of the GIO-NPs on different microbial strains, quantified by the $A_{620 \mathrm{~nm}}$ values (the pointed area indicates the direct correlation between the tested concentration and the bacterial growth stimulatory effect).

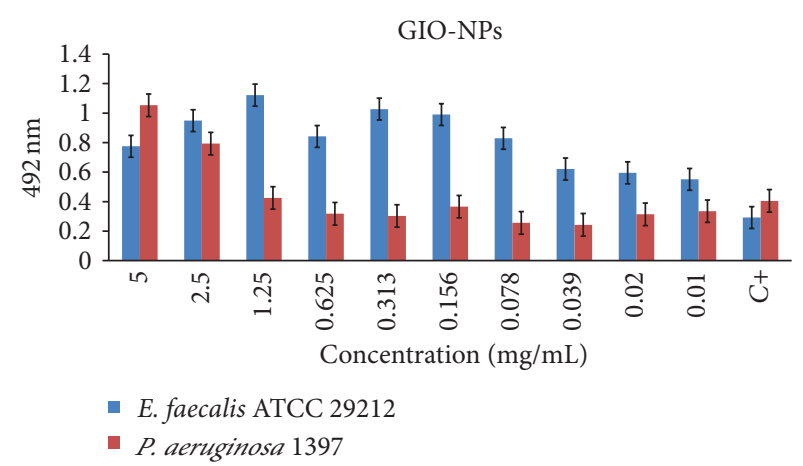

FIGURE 5: The quantitative assay of the inhibitory effect of GIO-NPs on biofilms developed on the inert substratum by different microbial strains, quantified by the $A_{490 \mathrm{~nm}}$ values.

case of $P$. aeruginosa 1397 biofilms, at low concentrations, the glycerol iron oxide inhibited the ability of this strain to develop biofilms on the inert substratum. 


\section{Acknowledgments}

The authors would like to thank Professor Mariana Carmen Chifiriuc of Microbiology Immunology Department, Faculty of Biology, and University of Bucharest for assistance with antimicrobial tests and for the constructive discussions. This work was supported by the Ministry of Education of Romania, Project no. C2-06 under program CEA-IFA.

\section{References}

[1] A. Kapri, M. G. H. Zaidi, A. Satlewal, and R. Goel, "SPIONaccelerated biodegradation of low-density polyethylene by indigenous microbial consortium," International Biodeterioration and Biodegradation, vol. 64, no. 3, pp. 238-244, 2010.

[2] A. Figuerola, R. Di Corato, L. Manna, and T. Pellegrino, "From iron oxide nanoparticles towards advanced iron-based inorganic materials designed for biomedical applications," Pharmacological Research, vol. 62, no. 2, pp. 126-143, 2010.

[3] G. Nicoara, D. Fratiloiu, M. Nogues, J. L. Dormann, and F. Vasiliu, "Ni-Zn ferrite nanoparticles prepared by ball milling," Materials Science Forum, vol. 235-238, no. 1, pp. 145-150, 1997.

[4] D. Prodan, C. Chanéac, E. Tronc et al., "Adsorption phenomena and magnetic properties of $\gamma-\mathrm{Fe}_{2} \mathrm{O}_{3}$ nanoparticles," Journal of Magnetism and Magnetic Materials, vol. 203, no. 1-3, pp. 63-65, 1999.

[5] D. Prodan, V. V. Grecu, M. N. Grecu, E. Tronc, and J. P. Jolivet, "Electron spin resonance in $\gamma-\mathrm{Fe}_{2} \mathrm{O}_{3}$ nanoparticles dispersed in a polymer matrix," Measurement Science and Technology, vol. 10, no. 9, pp. L41-L43, 1999.

[6] D. Predoi, V. Kuncser, and G. Filoti, "Magnetic behaviour of maghemite nanoparticles studied by Mössbauer spectroscopy," Romanian Reports in Physics, vol. 56, no. 3, pp. 373-378, 2004.

[7] R. Qiao, C. Yang, and M. Gao, "Superparamagnetic iron oxide nanoparticles: from preparations to in vivo MRI applications," Journal of Materials Chemistry, vol. 19, no. 35, pp. 6274-6293, 2009.

[8] J. Park, K. An, Y. Hwang et al., "Ultra-large-scale syntheses of monodisperse nanocrystals," Nature Materials, vol. 3, no. 12, pp. 891-895, 2004.

[9] C. Xu, Z. Yuan, N. Kohler, J. Kim, M. A. Chung, and S. Sun, "FePt nanoparticles as an Fe reservoir for controlled Fe release and tumor inhibition," Journal of the American Chemical Society, vol. 131, pp. 15346-15351, 2009.

[10] C. Xu, J. Xie, D. Ho, C. Wang, N. Kohler, E. G. Walsh et al., "Au- $\mathrm{Fe}_{3} \mathrm{O}_{4}$ dumbbell nanoparticles as dual-functional probes," Angewandte Chemie International Edition, vol. 47, pp. 173-176, 2008.

[11] M. Oka, T. Tomioka, K. Tomita, A. Nishino, and S. Ueda, "Inactivation of enveloped viruses by a silver-thiosulfate complex," Metal-Based Drugs, vol. 1, p. 511, 1994.

[12] A. Oloffs, C. Grosse-Siestrup, S. Bisson, M. Rinck, R. Rudolph, and U. Gross, "Biocompatibility of silver-coated polyurethane catheters and silvercoated Dacron material," Biomaterials, vol. 15, no. 10, pp. 753-758, 1994.

[13] M. Flores, N. Colón, O. Rivera et al., " A study of the growth curves of C. xerosis and E. coli Bacteria in Mediums Containing Cobalt Ferrite Nanoparticles," Materials Research Society, p. 820, 2004.

[14] D. N. Williams, S. H. Ehrman, and T. R. P. Holoman, "Evaluation of the microbial growth response to inorganic nanoparticles," Journal of Nanobiotechnology, vol. 4, article 3, 2006.
[15] W. Jiang, H. Mashayekhi, and B. Xing, "Bacterial toxicity comparison between nano- and micro-scaled oxide particles," Environmental Pollution, vol. 157, no. 5, pp. 1619-1625, 2009.

[16] R. Massart, "Magnetic fluids and process for obtaining them," US Patent 4329241, 1982.

[17] R. Massart, "Preparation of aqueous magnetic liquids in alkaline and acidic media," IEEE Transactions on Magnetics, vol. 17, pp. 1247-1248, 1981.

[18] R. Massart, J. Roger, and V. Cabuil, "New Trends in Chemistry of Magnetic Colloids: Polar and Non Polar Magnetic Fluids, Emulsions, Capsules and Vesicles," Brazilian Journal of Physics, vol. 25, no. 2, pp. 135-141, 1995.

[19] D. Predoi and C. M. Valsangiacom, "Thermal studies of magnetic spinel iron oxide in solution," Journal of Optoelectronics and Advanced Materials, vol. 9, no. 6, pp. 1797-1799, 2007.

[20] D. Zins, V. Cabuil, and R. Massart, "New aqueous magnetic fluids," Journal of Molecular Liquids, vol. 83, no. 1-3, pp. 217-232, 1999.

[21] C. Limban and M. C. Chifiriuc, "Antibacterial activity of new dibenzoxepinone oximes with fluorine and trifluoromethyl group substituents," International Journal of Molecular Sciences, vol. 12, no. 10, pp. 6432-6444, 2011.

[22] M. C. Chifiriuc, C. Stecoza, L. Veronica, O. Dracea, C. Larion, and A. M. Israil, "Antimicrobial activity of some new Oacyloximino-dibenzo[b,e]thiepins and O-acyloximino-dibenzo[b,e]thiepin-5,5-dioxides against planktonic cells," Romanian Biotechnological Letters, vol. 15, no. 2, pp. 5134-5139, 2010.

[23] L. Marutescu, C. Limban, M. C. Chifiriuc, A. V. Missir, I. C. Chirita, and M. T. Caproiu, "Studies on the antimicrobial activity of new compounds containing thiourea function," Biointerface Research in Applied Chemistry, vol. 1, no. 6, pp. 236-241, 2011.

[24] C. Limban, L. Marutescu, and M. C. Chifiriuc, "Synthesis, spectroscopic properties and antipathogenic activity of new thiourea derivatives," Molecules, vol. 16, no. 9, pp. 7593-7607, 2011.

[25] M. C. Chifiriuc, M. M. Mitache, Badea et al., "Microlevel study for the assessment of the economic impact of resistance to disinfectants used in the hospital environment and evaluation of new alternatives," Ege Academic Review, vol. 9, no. 3, pp. 955-959, 2009.

[26] R. M. Cornell and U. Schertmann, Preparation and Characterisation, VCH, Weinheim, Germany, 1991.

[27] E. Nor Hidawati and A. M. M. Sakinah, "Treatment of glycerin pitch from biodiesel production," International Journal of Chemical and Environmental Engineering, vol. 2, no. 5, pp. 309-313, 2011.

[28] J. Hradil, A. Pisarev, M. Babič, and D. Horák, "Dextranmodified iron oxide nanoparticles," China Particuology, vol. 5, no. 1-2, pp. 162-168, 2007.

[29] M. L. Hair, "Hydroxyl groups on silica surface," Journal of NonCrystalline Solids, vol. 19, pp. 299-309, 1975.

[30] E. Barrado, F. Prieto, J. Medina, and F. A. Lopez, "Characterisation of solid residues obtained on removal of $\mathrm{Cr}$ from waste water," Journal of Alloys and Compounds, vol. 335, pp. 203-209, 2002.

[31] J. L. Martin de Vidales, A. Lopez-Delgado, E. Vila, and F. A. Lopez, "The effect of the starting solution on the physicochemical properties of zinc ferrite synthesized at low temperature," Journal of Alloys and Compounds, vol. 287, pp. 276-283, 1999. 
[32] D. Predoi, "A Study On Iron Oxide Nanoparticles Coated With Dextrin Obtained By Coprecipitation," Digest Journal of Nanomaterials and Biostructures, vol. 2, no. 1, p. 169, 2007.

[33] T. Gordon, B. Perlstein, O. Houbara, I. Felner, E. Banin, and S. Margel, "Synthesis and characterization of zinc/iron oxide composite nanoparticles and their antibacterial properties," Colloids and Surfaces A, vol. 374, no. 1-3, pp. 1-8, 2011.

[34] R. M. Donlan and J. W. Costerton, "Biofilms: survival mechanisms of clinically relevant microorganisms," Clinical Microbiology Reviews, vol. 15, no. 2, pp. 167-193, 2002.

[35] V. Lazăr and M. C. Chifiriuc, "Medical significance and new therapeutical strategies for biofilm associated infections," Roumanian Archives of Microbiology and Immunology, vol. 69, no. 3, pp. 125-138, 2010.

[36] M. Singh, S. Singh, S. Prasad, and I. S. Gambhir, "Nanotechnology in medicine and antibacterial effect of silver nanoparticles," Digest Journal of Nanomaterials and Biostructures, 3, pp. 115-122, 2008. 

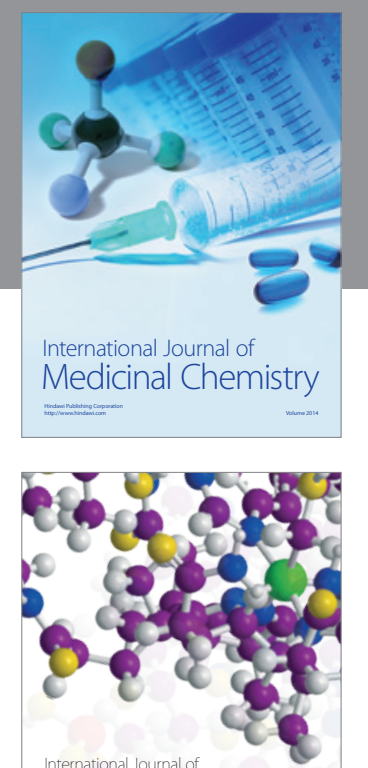

\section{Carbohydrate} Chemistry

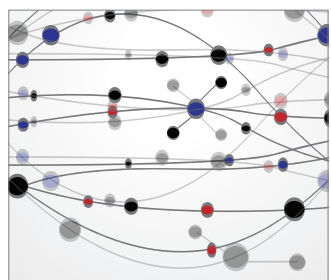

The Scientific World Journal
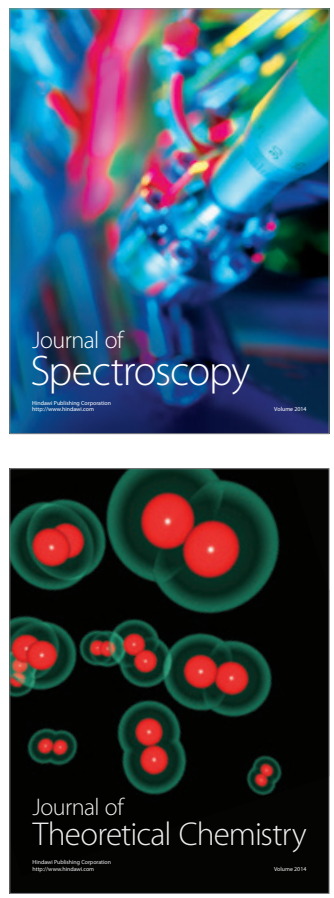
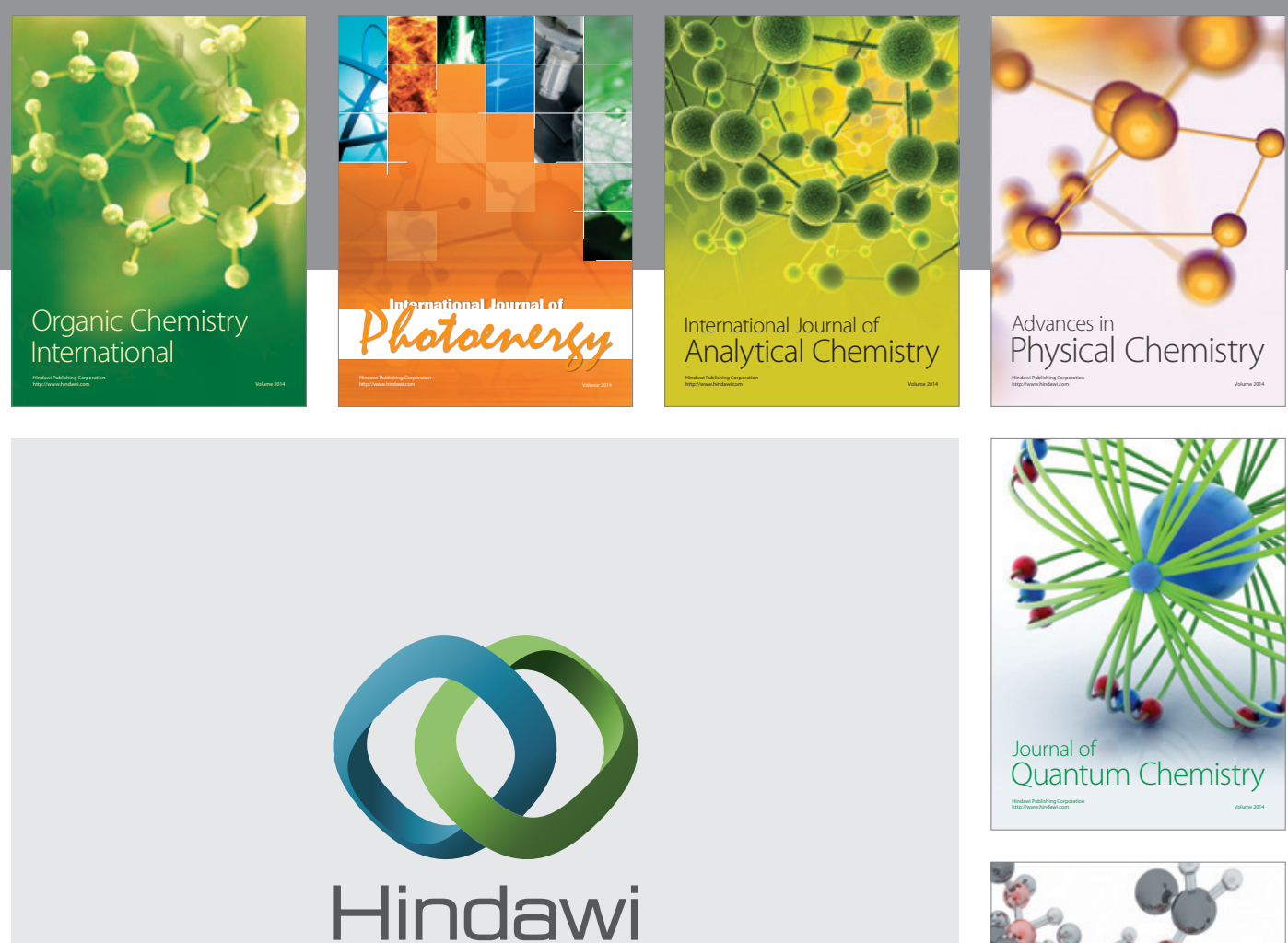

Submit your manuscripts at

http://www.hindawi.com

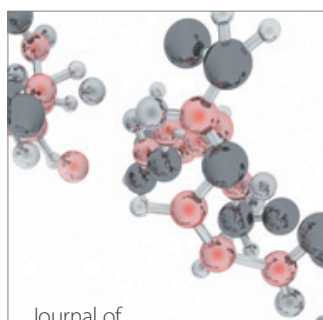

Analytical Methods

in Chemistry

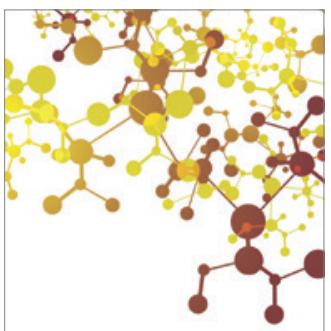

Journal of

Applied Chemistry

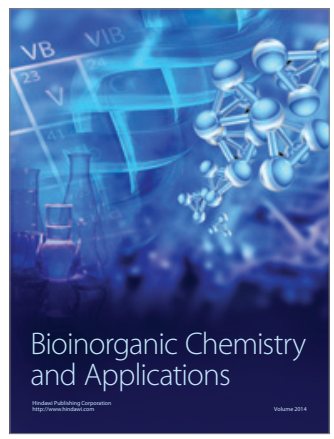

Inorganic Chemistry
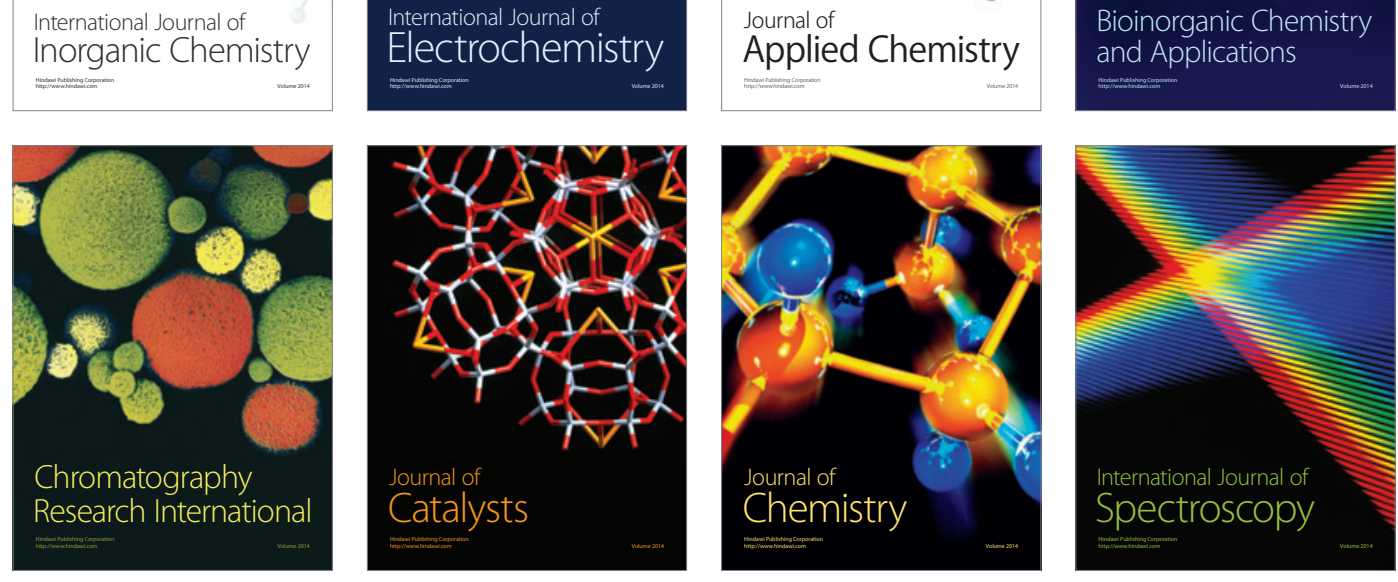